\title{
Comparative study on effectiveness of lecture using Powerpoint versus lecture cum demonstration on knowledge and skill regarding cranial nerve assessment among B.Sc nursing students
}

\author{
Aparna Pandey ${ }^{1^{*}}$, Vijaya Kumar $S^{2}$ \\ ${ }^{1,2}$ Professor, Dept. of Nursing, ${ }^{1}$ Sahara College of Nursing and Paramedical Sciences, Lucknow, Uttar Pradesh, ${ }^{2}$ Siddaganga College of \\ Pharmacy, Karnataka, India
}

*Corresponding Author: Aparna Pandey

Email: 0510aparna@gmail.com

\begin{abstract}
Teaching learning process are interdependent on one another for an effective learning to take place an effective teaching is necessary similarly teaching cannot take place without an idea of learning. ${ }^{1}$ With a focus to identify an effective teaching method comparison between the traditional teaching methods with computer aided learning this study was done. A total of 400 students studying in various nursing colleges formed the sample of this study. The students were divided into the experimental and control group and a self-prepared MCQ along with observation check list was used to assess the knowledge and skills of the nursing students. On analysis both the methods were found to be equally effective in enhancing the knowledge and skills of the students but lecture using PowerPoint was more effective than lecture cum demonstration.
\end{abstract}

Keywords: Lecture, Demonstration, Power Point, Knowledge, Skill, Cranial nerve assessment.

\section{Introduction}

Teaching and learning is a process whereby the society gives training in a selected environment to the young generation in a quick manner and helps them to enable themselves to adjust to the world in which they live. Hence we can say that this process helps to train good and responsible youngsters, who can contributed towards the growth and welfare of the country. $^{2}$

The process of teaching and learning is said to be fruitful only if it is related to the real life situations in totality, teacher always plays a crucial role in imparting the knowledge to the learners and this is possible only when they are able to take into account the needs of the learner. Only once the teacher understands the need of the learner only then an effective teaching can take place. ${ }^{3}$ In nursing education the process of learning is always influenced by various factors such as the rules set by the nursing council, the policies made by the administrators, the facilities provided at the college to the students such as the classroom environment, the use of A.V Aids, the teaching faculty and at the same time the interest of the learner. These all factors may affect the process of delivering the knowledge as well as the quality of learning that is taking place in the institution. ${ }^{4}$ There may be certain extraneous factors that may also influence the learning like types of patients, interests and problems of the community and collective beliefs of those involved in the education program. ${ }^{5}$ So while preparing the lessons and while delivering the lecture the teacher has to take into consideration all these factors and only then the teaching will be effective and the goal that has been set will be achieved.

\section{Need for the Study}

In the world of technical advancement where many of the schools are coming up with the concept of smart classes, still many of the nursing institutes are following the traditional method of lecture cum demonstration as a means of imparting knowledge to the students and being a teacher and a researcher I feel that this method is not much effective where the classroom size is more. Lecture cum demonstration method of teaching can be used effectively where the classroom size is less, an equal attention can be paid to all the students by dividing them into groups of ten, whereas if the classroom size is more dividing the students into groups would require more time to be spent by the teacher for a particular procedure. ${ }^{6}$

There is a very famous saying of cofucius which meant that whatever we listen we forget that easily but whatever we see we remember it for a long time and whichever activity we perform we remember it always in other words we become perfect in that activity. Hence, if we imply the same into the nursing curriculum but in a modified way we can change the way in which the students were learning earlier.

\section{Objectives of the Study}

1. To develop a tool on cranial nerve assessment.

2. To evaluate the pre-test knowledge and skill on cranial nerve assessment among B.Sc. Nursing students.

3. To evaluate the efficacy of lecture using PPT on cranial nerve assessment among B.Sc. Nursing students.

4. To evaluate the efficacy of lecture cum demonstration on cranial nerve assessment among B.Sc. Nursing students.

5. To compare the efficacy of lecture using PPT and lecture cum demonstration on knowledge and skill on cranial nerve assessment among B.Sc. Nursing students.

6. To find out the interrelationship between pre-test knowledge score with selected demographic variables.

\section{Materials and Methods}

Quasi-experimental research design was chosen for this study. Sample size was $4003^{\text {rd }}$ year B.Sc nursing students. The technique that was used for selecting the samples was the convenient sampling method. ${ }^{7}$ Prior to the collection of data 
the authorization was taken from the concerned authorities of the chosen institutes. The relevant data was gathered with the use of structured questionnaire prepared by the researcher and observation check list. Teaching was delivered to both the group using the relevant technique that was needed to be compared after preparing a lesson plan on cranial nerve assessment. The relevant information that was gathered was analyzed by using descriptive and inferential statistics.

\section{Results}

Initially in pre test the knowledge was ranging within 7-17 with mean 10.92 and SD of 2.69 experimental group and the similar outcome of range 7-17 with mean 10.68 and SD of 2.63. The mean percentage was $39.0 \%$ in experimental group and $38.1 \%$ in control group. Regarding pre test skill on cranial nerve assessment was ranging within 5-18 with mean 10.30 and SD of 2.91 in experimental group. In control group it was ranging from 6-16 with mean 9.98 and SD of 2.78. The mean percent was $36.7 \%$ in experimental group and in control group it was $35.6 \%$.

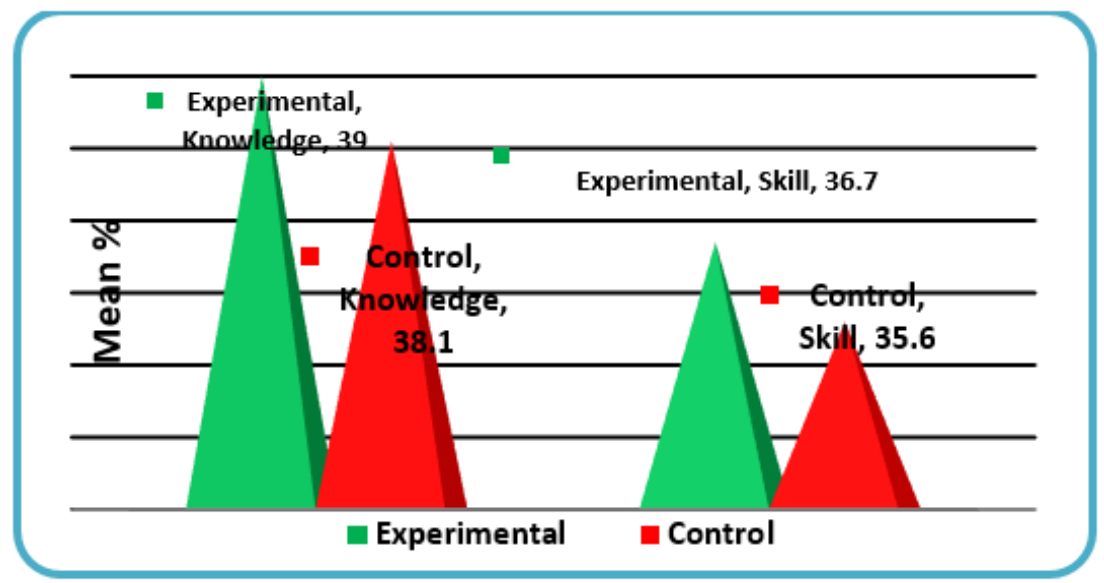

Fig. 1: Depicting range, mean and SD of pre test knowledge and skill on cranial nerve assessment among BSc Nursing students.

Table 1: Range, mean and SD of pre test knowledge and skill on cranial nerve assessment among BSc Nursing students.

\begin{tabular}{|l|l|c|c|c|c|c|c|c|c|}
\hline \multirow{2}{*}{ S. No. } & \multirow{2}{*}{ Variable } & Experimental & Control & \multicolumn{1}{|c|}{} \\
\cline { 3 - 10 } & & Range & Mean & SD & Mean\% & Range & Mean & SD & Mean\% \\
\hline 1 & Knowledge & $7-17$ & 10.92 & 2.69 & 39.0 & $7-17$ & 10.68 & 2.63 & 38.1 \\
\hline 2 & Skill & $5-18$ & 10.30 & 2.91 & 36.7 & $6-16$ & 9.98 & 2.78 & 35.6 \\
\hline
\end{tabular}

Table 2: Range, mean and SD of post test knowledge and skill on cranial nerve assessment among BSc Nursing students.

\begin{tabular}{|l|l|c|c|c|c|c|c|c|c|}
\hline \multirow{2}{*}{ S. No } & \multirow{2}{*}{ Variable } & Range & Mean & SD & $\begin{array}{c}\text { Mean } \\
\boldsymbol{\%}\end{array}$ & Range & Mean & SD & $\begin{array}{c}\text { Mean } \\
\boldsymbol{\%}\end{array}$ \\
\hline 1 & Knowledge & $15-27$ & 20.66 & 3.30 & 73.7 & $12-24$ & 18.65 & 2.89 & 66.6 \\
\hline 2 & Skill & $11-27$ & 18.77 & 4.00 & 67.1 & $12-25$ & 15.80 & 2.65 & 56.4 \\
\hline
\end{tabular}

Initially in post test the knowledge was ranging within 15-27 with mean 20.66 and SD of 3.30 experimental group it was found to be more than the post test outcomes of range 12-24 with mean 18.65 and SD of 2.89. And also the mean percentage was73.7\% in experimental group was greater than the mean percent of $66.6 \%$ in control group. Regarding post test skill on cranial nerve assessment was ranging within 11-27 with mean 18.77 and SD of 4.00 in experimental group it was also found to be greater than the outcomes found in control group the range of 12-25 with mean 15.80 and SD of 2.65 . The mean percent was $67.1 \%$ in experimental group and in control group it was $56.4 \%$.

It evidenced, the post test knowledge and skill was more in experimental group than found in control group.

Table 3: Comparison of post test scores of knowledge and skill for statistical significance in between the groups.

\begin{tabular}{|l|c|c|c|c|c|c|c|}
\hline \multirow{2}{*}{ S.No } & \multirow{2}{*}{ Variables } & \multicolumn{2}{|c|}{ Experimental } & \multicolumn{2}{c|}{ Control } & Unpaired & \multirow{2}{*}{ p-value } \\
\cline { 3 - 6 } & & Mean & SD & Mean & SD & t-value & \\
\hline 1 & Knowledge & 20.66 & 3.30 & 18.65 & 2.89 & $\mathrm{t}=6.42$ & $\mathrm{p}<0.05$ \\
\hline 2 & Skill & 18.77 & 4.00 & 15.80 & 2.65 & $\mathrm{t}=4.96$ & $\mathrm{p}<0.05$ \\
\hline
\end{tabular}




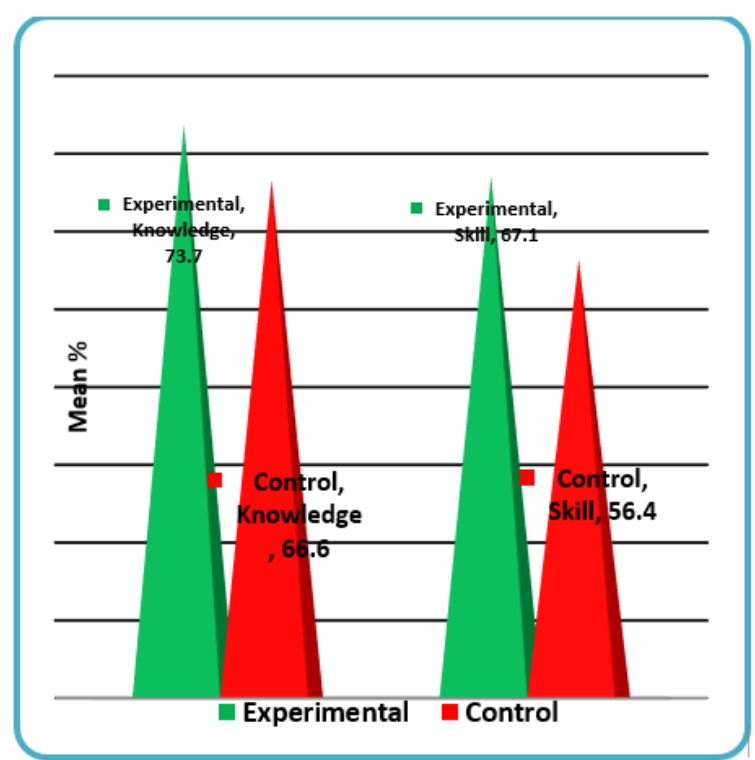

Fig. 2: Depicting Range, mean and SD of post test knowledge and skill on cranial nerve assessment among BSc Nursing students

It was found that the experimental and control groups were found to be individually efficient in itself in improving the knowledge and skill of the student nurses regarding cranial nerve assessment, and this was established using the unpaired t-test to compare the post test scores for statistical significance. The knowledge post-test mean was 20.66 in experimental group that was comparably more than the posttest means score of control group which was18.65. The t-test value for the knowledge was found to be 6.42 with p-value less than 0.05 hence it was statistically significant at $p<0.05$. Likewise, the post-test skill mean score was 18.77 that were comparably more in experimental group than in control group that was 15.80 . The $\mathrm{t}$-value was 4.96 at $\mathrm{p}$-value less than 0.05 which established its statistical significance at $\mathrm{p}<0.05$.

\section{Discussion}

The pre-test knowledge score revealed that the students were having average knowledge regarding cranial nerve assessment and the knowledge score ranged between 7-17 both in the experimental group and the control group while the skill score ranged between 5-18 in experimental group and 6-16 in control group. Which revealed that the pre-test knowledge and skill score was more or less the same in both groups.

The post-test knowledge score was between 15-27 in experimental group and skill score was between 11-27 which revealed an enhancement in both the knowledge and skill while in the control group the knowledge score was between 12-24 and skill score was 12-25 that showed an enhancement in the score. This indicated that both the methods of teaching were individually effective in enhancing the knowledge.

The post test score of both experimental and control group were compared which revealed that post-test mean score of knowledge for the experimental group was 20.66 which was comparably more than the mean score of control group which was 18.65 with $\mathrm{t}$ value 6.42 at $\mathrm{p}$ less than 0.05 which shows statistical significance. Similarly the post-test mean score of skill for the experimental group was 18.77 which was comparably more than the mean score of control group which was 15.80 with $t$ value 4.96 at $p$ less than 0.05 which shows statistical significance.

The results of this study reveal that both the experimental and control group were individually efficient enough in enhancing the knowledge and skill of the $3^{\text {rd }}$ year graduate student nurses regarding cranial nerve assessment, but the experimental group was significantly better than control group in enhancing the knowledge and skill.

\section{Recommendations}

A comparative study can be conducted to compare other methods of teaching like project method, group discussion, seminar, role-play, simulation etc. ${ }^{8}$

1. A study can be conducted to identify the attitude of the students towards the method of teaching being employed in their nursing institute. ${ }^{9}$

2. A study can be conducted to identify the effect various methods of teaching being employed in various nursing colleges on the knowledge and skills of the students.

3. A Similar study can be conducted on other students studying in various other professional colleges.

4. A study can be conducted on the teaching and learning resources available at various nursing institutes. ${ }^{10}$

5. A study can be conducted on the teaching method being employed by the teachers and students satisfaction.

\section{Conclusion}

The following conclusion was drawn on the basis of this study in which lecture using PowerPoint was compared with the lecture cum demonstration on knowledge and skill regarding cranial nerve assessment among B.Sc. nursing 
students to assess the effectiveness of lecture using PowerPoint. Either of the methods of teaching when seen individually were equally effective in enhancing the knowledge and skill of the student nurses. But on comparison it was found the lecture using PowerPoint was a bit better than Lecture cum demonstration. So it can be concluded that depending upon the demand and need of the students any of these methods can be used for teaching the students or if needed a combination of both the methods can be used, which would be more beneficial for the students. Similar studies can also be conducted using various other methods of teaching. The findings of which may be beneficial for the students as well as the teachers so as to implement the best method of teaching and learning.

\section{Source of Funding}

None.

\section{Conflict of Interest}

None.

\section{References}

1. Shankarnarayan B, Sindhu B. Learning and teaching nursing, brainfill publishers, second edition, page 115-43.

2. Kaur K, Singh NV, Ghai S, Agnihotri M. A comparative study to assess the effectiveness of Live Demonstration and Video Assisted Teaching on nasogastric tube feeding on the skill development of nursing students. Nurs Midwifery Res $J$. 2015;11(4):163-74.
3. Mangal SK, Uma M. Essentials of educational technology, PHI learning private limited, second edition, 2010;239-50.

4. Basvanthappa BT. Nursing Education, Jaypee Publishers, First edition, p. 277-17.

5. Neeraja KP. Textbook of nursing education, jaypee brothers medical publisher (P) Ltd, first edition, 2003;53-81.

6. Bloomfield JG, While AE, Roberts JD. Using computer assisted learning for clinical skills education in nursing: integrative review. J Adv Nurs. 2008;63(3):222-35.

7. Kothari CR. Research methodology methods and techniques" New Delhi, New age international publishers, $2^{\text {nd }}$ edition; 2004.

8. Arundhathi S, Padma K, Rani UK, Kezia J. A study to assess the effectiveness of structured teaching programme among $3 \mathrm{rd}$ year b.sc (n) students regarding Neurological assessment of patients with brain stroke in selected Nursing college's at Kurnool. Int J Multidiscip Educ Res. 2016;1(4):19-21.

9. Sanatombi DE. Nursing Students' perception of effective teaching methods in learning pharmacology. Nightingale Nurs Times. 2010;6(4):45-9.

10. Hilal Z, Kumpernatz AK, Rezniczek GA, Cetin C, TempferBentz EK, Tempfer CB. A randomized comparison of video demonstration versus hands-on training of medical students for vacuum delivery using objective structured assessment of technical skills. Med. 2017;96(11):e6355.

How to cite: Pandey A, Kumar VS. Comparative study on effectiveness of lecture using Powerpoint versus lecture cum demonstration on knowledge and skill regarding cranial nerve assessment among B.Sc nursing students. J Educ Technol Health Sci. 2020;7(1):29-32. 